\title{
A RESPONSABILIDADE CIVIL DAS CONCESSIONÁRIAS DE ENERGIA ELÉTRICA QUANTO AOS DANOS AOS CONSUMIDORES E A NECESSIDADE DE FORTALECIMENTO DA ATUAÇÃO DOS ÓRGÃOS DE DEFESA COLETIVA
}

\author{
Dennis Verbicaro ${ }^{1}$ \\ Gabriela Ohana ${ }^{2}$
}

\section{RESUMO:}

O artigo através do método dedutivo, levantamento da dados, bibliografias e jurisprudências, analisa acerca da responsabilidade cível-consumerista das concessionárias de energia elétrica quanto aos danos ocasionados aos consumidores referentes as cobranças irregulares de débitos e a necessidade de fortalecimento da atuação dos órgãos de defesa coletiva. Explana pontualmente sobre a essencialidade do fornecimento de energia elétrica e as irregularidades nas cobranças de débitos, o panorama judicial da pulverização de ações individuais, por consequente, a (in)eficiência da atuação regulatória da ANEEL, ressaltando ainda, sobre a atuação dos órgãos coletivos em prol da defesa do direito dos consumidores de energia elétrica.

PALAVRAS-CHAVE: Consumidor. Energia Elétrica. ANEEL. Responsabilidade Civil. Tutela coletiva.

\section{THE CIVIL LIABILITY OF ELECTRICITY DEALER IN RESPECT OF DAMAGE TO CONSUMERS AND THE NEED FOR STRENGTHENING COLLECTIVE DEFENSE BODIES}

\begin{abstract}
:
The article through the deductive method, data collection, bibliographies and jurisprudence, analyzes about the civil-consumerist responsibility of the electric utilities regarding the damages caused to the consumers regarding the irregular collection of debts and the need to strengthen the defense agencies performance. collective. Punctually explains about the essentiality of the electricity supply and the irregularities in the collection of debts, the judicial panorama of the pulverization of individual actions, consequently, the (in) efficiency of ANEEL's regulatory performance, and also stresses the actions of the collective bodies. for the defense of the right of consumers of electricity.
\end{abstract}

KEYWORDS: Consumer. Electricity. ANEEL. Civil Responsability. Collective Tutelage.

\footnotetext{
* Doutor em Direito do Consumidor pela Universidade de Salamanca (ES). Mestre em Direito do Consumidor pela Universidade Federal do Pará - CESUPA. Professor da Graduação e dos Programas de Pós-Graduação Stricto Sensu da Universidade Federal do Pará-UFPA e do Centro Universitário do Pará-CESUPA. Procurador do Estado do Pará e Advogado. E-mail: dennis@gavl.com.br.

* Mestranda em Constitucionalismo, Democracia e Direitos Humanos pelo PPGD da UFPA. Bolsista CAPES Código de Financiamento 001. Pesquisadora do Grupo de Pesquisa "Consumo e Cidadania" - CNPQ. PósGraduada em Direito Público pelo Centro Universitário do Pará - CESUPA. Bacharel em Direito pela Universidade da Amazônia - UNAMA. Advogada. E-mail: gabi_andohana@hotmail.com.
} 


\section{INTRODUÇÃO}

Nos dias atuais tornou-se indissociável a ideia de uma sociedade sem a utilização de energia elétrica, uma vez que a prestação deste serviço público se transformou em essencial, além de intrinsecamente ligada ao desenvolvimento e à economia. Entretanto, por outro viés, entre o percurso da geração, distribuição e repasse de energia ao consumidor final não se pode esquecer das inúmeras demandas judiciais individuais acerca de irregularidades que ludibriam a medição correta por meio da unidade consumidora.

De modo geral, tais irregularidades acabam, não raras vezes, onerando a relação de consumo ao passo que as tarifas cobradas são faturadas pelas concessionárias de energia em valores a maior que o realmente devido, transferindo o percentual de perdas energéticas ao consumidor e contrariando as normativas que buscam um equilíbrio econômico-financeiro emitidas pela Agência Nacional de Energia Elétrica - ANEEL.

Ademais, o reflexo de determinadas falhas das fornecedoras de energia elétrica importam diretamente na prestação de forma inadequada do serviço, influindo na relação de consumo, na qual o consumidor, parte vulnerável da relação jurídica, descrito nos moldes do artigo $2^{\circ}$ do $\mathrm{CDC}$, em razão da percepção das atitudes da concessionária de energia sofre lesões patrimoniais e não patrimoniais, tal como o caso das cobranças com fito de recuperação de consumo, sendo obrigado a buscar o amparo judicial por meio de ações individuais, as quais a cada dia crescem numerosamente no Judiciário.

Nesse contexto, dentre outros variados problemas, utilizando-se do método dedutivo, levantamento bibliográfico nacional e estrangeiro e jurisprudências, recorta-se metodologicamente o objeto da pesquisa no que tange aos danos por cobranças por débitos irregulares, problematizando-se acerca da responsabilidade cível-consumerista das concessionárias de energia pela imputação unilateral de consumo não registrado e a consequente necessidade de fortalecimento de atuação dos órgãos de defesa coletiva, haja vista que as ações individuais sobre tal temática têm sido cada vez mais recorrentes no Judiciário e a tutela coletiva pode se manifestar como um mecanismo favorável à resolução das demanda acerca da aferição da medição irregular e dos valores cobrados.

\section{A ESSENCIALIDADE DO FORNECIMENTO DE ENERGIA ELÉTRICA E AS IRREGULARIDADES NAS COBRANÇAS DE RECUPERAÇÃO DE DÉBITOS}


Compreende-se que a prestação dos serviços públicos se encontra interligada à matéria administrativa, sendo também submetida aos parâmetros descritos no Código de Defesa do Consumidor - CDC. Nesse sentido, destaca-se que o fornecimento de energia elétrica acaba por ser considerado como um serviço público prestado para usuários determinados, com prestação específica e com a possibilidade de mensuração da sua utilização individual e, por esta razão, são remunerados por tarifa.

A tarifação do serviço é regulada pelo Código Tributário Nacional - CTN (BRASIL, 1966), pois, o preço cobrado é em troca de uma contraprestação específica do usuário pelo serviço utilizado. Enfatizando o exposto anteriormente, observa-se o posicionamento jurisprudencial do Superior Tribunal de Justiça - STJ encontrado no bojo da decisão emitida no Recurso Especial 463331/RO:

EMENTA: ADMINISTRATIVO E DIREITO CIVIL - PAGAMENTO DE SERVIÇO PÚBLICO (ENERGIA ELÉTRICA), PRESTADO POR CONCESSIONÁRIA.

1. Os serviços públicos prestados pelo próprio Estado e remunerados por taxa devem ser regidos pelo CTN, sendo nítido o caráter tributário da taxa.

2. Diferentemente, os serviços públicos prestados por empresas privadas e remuneradas por tarifas ou preço público regem-se pelas normas de Direito Privado e pelo CDC". 3 (Grifo nosso).

A caracterização da energia elétrica é de serviço público uti singuli ${ }^{4}$ e essencial, visto que segundo a Lei 7.783/89, vide art. 10, I, denomina-se, dentre muitos outros, que a distribuição de energia elétrica se trata de uma necessidade irremediável, imprescindível, que faz parte da sobrevivência da comunidade à luz da Dignidade da Pessoa Humana. Acerca do assunto sobre os serviços essenciais, esclarece Bandeira de Mello (2015, p. 600) que será toda atividade de oferecimento de utilidade ou comodidade material destinada à satisfação da coletividade em geral, fruível singularmente pelos administradores, e que o Estado assuma como pertinente à seus deveres, prestando por si mesmo ou por quem lhe faça às vezes, sob um regime de direito público.

Nesse sentido, o fornecimento de energia elétrica sob o regime das concessionárias de serviços públicos, em detrimento dos ensinamentos administrativos, trata-se da modalidade de

3 BRASIL. Superior Tribunal de Justiça - STJ. Recurso Especial 463331/RO. Disponível em: <https://stj.jusbrasil.com.br/jurisprudencia/19453464/recurso-especial-resp-463331-ro-2002-01100935>. Acesso em: 25 de Abril de 2017.

4 Tratam-se daqueles serviços públicos que são prestados à toda a coletividade, sem distinções, podendo ser individualizados em termos de mensuração de consumo pelo usuário que deste usufruiu, havendo então a possibilidade de cobrança de taxas e/ou tarifas, distribuindo-se o ônus da prestação. 
concessão simples firmada por meio de um contrato administrativo, através do qual se transfere a execução do serviço público à particulares, sejam estes Pessoas Jurídicas ou consórcio de empresas, que demonstrem capacidade para desempenhar a atividade transferida, exercendo por sua responsabilidade e por um determinado tempo o serviço, mediante a cobrança de tarifa dos usuários.

Regra geral compete aos entes da Administração Direta, seja a União, Estados, Municípios e Distrito Federal, a delegação de tal serviço aos particulares; contudo, excepcionalmente, a lei pode atribuir o poder delegatório para os entes da Administração Indireta, tal como em se tratando dos serviços de energia elétrica, cujo o poder é atribuído à Agência Nacional de Energia Elétrica - ANEEL, agência reguladora, portanto, autarquia federal em regime especial, atuante nos assuntos energéticos (CARVALHO, 2018, p. 656$657)$.

Por sua vez, a Constituição Federal de 1988 (BRASIL. 1988), em seu artigo 175, § único, inciso IV, estabelece que independente seja o Estado ou o delegatário o responsável pela execução do serviço público, deverá por obrigação o serviço ser prestado e mantido de modo adequado; sendo o texto constitucional reforçado nos ditames do artigo $6^{\circ}, \S^{\circ}$, da Lei 8.987/95, ao qual esboça que para o atendimento e satisfação da adequação deverão preservarse as condições de regularidade, continuidade, eficiência, segurança, atualidade, generalidade, cortesia na prestação e modicidade das tarifas.

No que tange ao consumidor, em relação ao Código de Defesa do Consumidor - CDC (BRASIL, 1990) é necessário primeiramente tecer algumas considerações. O conceito de consumidor está disposto no art. $2^{\circ}$ do $\mathrm{CDC}$, sendo considerado toda pessoa física, seja a pessoa natural, ou a pessoa jurídica que adquire ou utiliza produto ou serviço como destinatário final. Ademais, esclarece Rizzatto Nunes (2018, p. 119) que "quanto a esta última, como a norma não faz distinção, trata-se de toda e qualquer pessoa jurídica, quer seja uma microempresa, uma multinacional, pessoa jurídica civil ou comercial, associação, fundação, etc.”.

Sob esses aspectos, o uso de energia elétrica viabilizado pelas concessionárias ao consumidor somente formalizará uma relação de consumo para aquele que solicitar que a concessionária lhe forneça o serviço responsabilizando-se pelo pagamento da contraprestação que deverá ser realizado em virtude da utilização dos serviços prestados. Contudo, ressalte-se 
que a cobrança dessa tarifa deve ser exclusivamente para remunerar os investimentos realizados, pela disponibilidade e pela qualidade do serviço.

No mérito da qualidade do serviço é importante frisar que este é um dos direitos básicos do consumidor e pode ser analisado de acordo com a previsão no art. $6^{\circ}, \mathrm{X}, \mathrm{CDC}$, em que se dispõe que será direito consumerista a adequada e eficaz prestação dos serviços públicos em geral. Note-se ainda, que face aos serviços públicos o artigo 22 do CDC regrou especificamente sobre a obrigação no fornecimento adequado, eficiente, seguro e contínuo, em se tratando de serviços essenciais.

Por ser um serviço prestado por delegatários, enquanto à energia elétrica, incumbe ao Estado a fiscalização da atividade. Assim, vislumbrando a execução fiscalizatória, a regulamentação e adequação do serviço, a Agência Nacional de Energia Elétrica - ANEEL, reguladora responsável pela emissão de normativas e padrões técnicos em matéria de energia elétrica, expede constantemente atos que delimitam os direitos e deveres tanto para o consumidor quanto a concessionária de serviço público, bem como os procedimentos a serem adotados sobre as medições, faturamentos, e dentre outros sobre as fraudes no consumo e as cobranças de recuperação de consumos não faturados.

As irregularidades de consumo não são causas novas a serem discutidas no âmbito da responsabilização civil, as ligações diretas, o desvio de energia, a ruptura de selos/lacres, a adulteração de medidores, a medição irregular são algumas das hipóteses pelas quais cabe a concessionária de energia a investigação/apuração do ocorrido para posterior faturamento e cobrança ao consumidor.

Em se tratando do consumo não faturado por medição irregular entende-se que o consumo efetivamente fora realizado, porém, por algum procedimento falho o medidor não conseguiu efetivar a medição correta dos $\mathrm{Kw} / \mathrm{h}$ de determinada unidade consumidora, assim, nos termos dos artigos 104 da Resolução no 456/2000 (já revogada), e artigo 167, III da Resolução 414/2010, ambas da ANEEL, o procedimento irregular, seja este qual for, que provoque danos aos equipamentos de medição de consumo será imputado como de responsabilidade do consumidor, independente da autoria, veja-se:

Art. 104. O consumidor será responsável por danos causados aos equipamentos de medição ou ao sistema elétrico da concessionária, decorrentes de qualquer procedimento irregular ou de deficiência técnica das instalações elétricas internas da unidade consumidora.

Art. 167. O consumidor é responsável: 
III - pelos danos causados aos equipamentos de medição ou ao sistema elétrico da distribuidora, decorrentes de qualquer procedimento irregular ou deficiência técnica da unidade consumidora; $\mathrm{e}$

Veja-se que, tal responsabilização do usuário ultrapassa os limites de uma mera punição pela conduta inadequada, recaindo na esfera da cobrança de débito denominado de recuperação de consumo, auferida independente da apuração de culpa do consumidor, vez que a alegação supõe que este tenha vindo a se beneficiar pela medição a menor. De todo modo, para que haja a efetiva responsabilização do consumidor por suposto consumo a menor faz-se imprescindível que a concessionária de serviço público atue em conformidade com os ditames legais e regulamentados pela ANEEL, não bastando apenas a imputação de débito por meio de um dos funcionários ou da própria fornecedora de energia, sendo necessária a comprovação da alegação de fraude do aparelho medidor.

Nesse sentido, resgatam-se os ensinamentos da doutrina civilista sobre os elementos essenciais para a caracterização da apuração da responsabilidade, sendo estes: o fato/ação gerador do dano, o dano em si, quer seja o prejuízo material e/ou imaterial, o nexo de causalidade e a culpa. Nessa esteira, ainda, ressalta-se o ensinamento processualista incumbe o ônus probande quanto aos fatos ao autor, referente ao fato constitutivo de seu direito e ao réu, quanto à existência de fato impeditivo, modificativo ou extintivo do direito do autor, ressalvados os casos de inversão do ônus probande constantes nos regramentos do CDC e $\operatorname{artigos} 373, \S \S 1^{\circ}$ e $2^{\circ}$ do $\mathrm{CPC} / 15$.

Em outras palavras, quanto à inversão do ônus da prova, cabe a concessionária o ônus de provar o alegado, seja este, comprovar através de capacidade técnica e informativa o procedimento irregular constado na unidade consumidora, obedecendo assim o que preceitua o artigo $6^{\circ}$, VIII, do CDC. Sob essa ótica, é cediço o posicionamento dos Tribunais Estaduais acerca da comprovação da ilicitude no medidor por parte da concessionária, vejamos:

CIVIL - PRESTAÇÃO DE SERVIÇOS FORNECIMENTO DE ENERGIA ELÉTRICA - AÇÃO DECLARATÓRIA DE INEXIGIBILIDADE - VARIAÇÃO EXCESSIVA - DESCUMPRIMENTO, PELA CONCESSIONÁRIA, DO ÔNUS DE PROVAR A REGULARIDADE DO RELÓGIO MEDIDOR CONSUMO QUE DEVE LEVAR EM CONTA A MÉDIA DOS DOZE CICLOS ANTERIORES À FATURA IMPUGNADA, NOS MOLDES DA RES. 414/10. (TJSP. APL 0025504-12.2012.8.26.0576, 35 ${ }^{\mathrm{a}}$ Câmara de Direito Privado, Rel. Artur Marques, j. em 16/12/2013). ${ }^{5}$ (Grifo nosso)

\footnotetext{
5 BRASIL. Tribunal de Justiça de São Paulo - TJSP. TJSP. APL 0025504-12.2012.8.26.0576. Disponível em: <https://tj-sp.jusbrasil.com.br/jurisprudencia/451843408/apelacao-apl-322205520128260576-sp-00322205520128260576/inteiro-teor-451843532>. Acesso em 27 de abril de 2019.
} 
APELAÇÃO CÍVEL. RELAÇÃO DE CONSUMO. ENERGIA ELÉTRICA. DEMANDA OBJETIVANDO O CANCELAMENTO DO TERMO DE OCORRENCIA DE IRREGULARIDADE - TOI, LAVRADO UNILATERALMENTE PELA RÉ, QUE IMPUTOU À EMPRESA AUTORA DÉBITO NO VALOR DE R\$ R \$8.182,25, REFERENTE AO PERÍODO DE APURAÇÃO DE 23/02/2013 A 24/04/2017, ALEGANDO SUPOSTA IRREGULARIDADE NO MEDIDOR DE ENERGIA. SENTENÇA DE PROCEDÊNCIA, CANCELANDO O TOI EM QUESTÃO E CONDENẢNDO A RÉ A DEVOLVER EM DOBRO O VALOR INDEVIDAMENTE PAGO PELA AUTORA. RECURSO DA PARTE RÉ, PRETENDENDO A REFORMA TOTAL DO JULGADO. LAVRATURA UNILATERAL DO TERMO DE OCORRÊNCIA E INSPEÇÃO - TOI, SEM O CRIVO DO CONTRADITÓRIO, QUE RESTOU INCONTROVERSA NOS AUTOS. RESPONSABILIDADE OBJETIVA DA CONCESSIONÁRIA RÉ (§ $6^{\circ}$ DO ARTIGO 37 DA CR E ART. 14, CAPUT DO CDC), NÃO COMPETINDO AO CONSUMIDOR, PARTE MAIS FRÁGIL NA RELAÇÃO JURÍDICA, A DILAÇÃo PROBATÓRIA. TAMBÉM NÃO PODE O MESMO PROVAR QUE NÃO CONSUMIU A ALEGADA QUANTIDADE DE ENERGIA, TENDO EM VISTA A INVIABILIDADE DE SE PRODUZIR PROVA NEGATIVA. NO ENTANTO, NÃO SE DESINCUMBIU A RÉ DE SEU ÔNUS PROBATÓRIO, NÃO DEMONSTRANDO A OCORRÊNCIA DA ALEGADA IRREGULARIDADE NO MEDIDOR DA EMPRESA AUTORA, O QUAL, RESSALTE-SE, LOCALIZA-SE NA PARTE SUPERIOR DO POSTE EM FRENTE AO ESTABELECIMENTO COMERCIAL EM TELA, SENDO O ACESSO SOMENTE DA RÉ. TOI QUE, POR SI SÓ, É INSUFICIENTE PARA COMPROVAR O ALEGADO VÍCIO NO SISTEMA DE MEDIČ̃̃O DE ENERGIA ELÉTRICA, JÁ QUE NÃO GOZA DE PRESUNÇÃ̃O DE LEGITIMIDADE (SÚMULA 256 DO TJRJ). AUSÊNCIA DE CONFIRMAÇÃO POR PERÍCIA TÉCNICA POSTERIOR, CUJA IMPRESCINDIBILIDADE É RECONHECIDA PELA JURISPRUDÊNCIA DO SUPERIOR TRIBUNAL DE JUSTIÇA, BEM COMO POR ESTE TRIBUNAL. FALHA NA PRESTAÇÃO DO SERVIÇO CONFIGURADA. INFRINGÊNCIA DE NORMAS REGULADORAS DA MATÉRIA, CONTIDAS EM RESOLUÇÃO DA ANEEL, BEM COMO DOS DEVERES DE INFORMAÇÃO E TRANSPARÊNCIA. DÉBITO IMPOSTO AO CONSUMIDOR QUE NÃO SE SUSTENTA. [...] Processo APL 0194671-25.2017.8.19.0001 Órgão Julgador: VIGÉSIMA QUARTA CÂMARA CÍVEL Julgamento: 27 de fevereiro de 2019. RelatorDes(a). LUIZ ROBERTO AYOUB. ${ }^{6}$ (Grifo nosso)

Sob esse mesmo aspecto, pontualmente leciona o artigo 129 da Resolução 414/2010 ANEEL dispondo acerca da incumbência da prestadora de serviço público, devendo esta adotar todas as medidas necessárias à instrução do feito, seja desde a documentação de ocorrência da irregularidade até a perícia técnica e relatório que demonstre o prejuízo pelo consumo não faturado:

Art. 129. Na ocorrência de indício de procedimento irregular, a distribuidora deve adotar as providências necessárias para sua fiel caracterização e apuração do consumo não faturado ou faturado a menor.

$\S 1$ o A distribuidora deve compor conjunto de evidências para a caracterização de eventual irregularidade por meio dos seguintes procedimentos:

\footnotetext{
${ }^{6}$ BRASIL. Tribunal de Justiça do Rio de Janeiro - TJ-RJ. APELAÇÃO: APL 0194671-25.2017.8.19.0001. Disponível em: <https://tj-rj.jusbrasil.com.br/jurisprudencia/719109860/apelacao-apl-1946712520178 190001 ? refserp\&s= paid $>$. Acesso em: 27 jul. 2019.
} 
I - emitir o Termo de Ocorrência e Inspeção - TOI, em formulário próprio, elaborado conforme Anexo V desta Resolução;

II - solicitar perícia técnica, a seu critério, ou quando requerida pelo consumidor ou por seu representante legal;

III - elaborar relatório de avaliação técnica, quando constatada a violação do medidor ou demais equipamentos de medição, exceto quando for solicitada a perícia técnica de que trata o inciso II;

IV - efetuar a avaliação do histórico de consumo e grandezas elétricas;

V - implementar, quando julgar necessário, os seguintes procedimentos;

Assim, quando da verificação de possível irregularidade o consumidor deve receber uma cópia do Termo de Ocorrência - TOI, devendo recibar o documento para garantir a autenticidade, podendo manifestar a opção pela perícia técnica particular a ser realizada no medidor e ciência nos casos de retirada do equipamento; e para além de receber o TOI, deverá ser informado sobre a data da inspeção técnica pública para poder acompanhá-la ou encaminhar representante, exercendo então o direito constitucional ao contraditório e possível contestação em prol da ampla defesa, conforme art.129, $\S 2^{\circ}, \S 4^{\circ}$ e $\S 5^{\circ}$ da Resolução 414/10 ANEEL.

Ocorre que, não raras vezes, as concessionárias de energia elétrica, embora cientes das regulamentações, frequentemente descumprem os dispositivos legais, principalmente no tocante a ampla defesa e ao contraditório, viciando o procedimento que, em tese, provaria as alegações sobre o consumo não faturado e fundamentaria a recuperação deste. Ademais, não obstante a prevalência de considerar o débito plenamente exigível, as concessionárias elaboram os cálculos de cobrança e encaminham ao consumidor, que figurando no polo mais fraco da relação, não consegue ser hipossuficiente ao ponto de provar a ausência da irregularidade e face aos valores exorbitantes não consegue quitar o débito, logo, a fornecedora valendo-se da apuração unilateral e do não pagamento determina a inscrição do nome do usuário nos cadastros de proteção e a consequente suspensão do fornecimento de energia, ambos como mecanismos de forçar a quitação da suposta dívida.

O Superior Tribunal de Justiça - STJ já firmou posicionamento nesse sentido, afirmando a ilegalidade na atitude das concessionárias de energia quando procedem com a suspensão do fornecimento baseadas em apuração unilateral:

IMPOSSIBILIDADE DE EXAME EM RECURSO ESPECIAL. INTERRUPÇÃO DO SERVIÇO. FRAUDE. VERIFICAÇÃO UNILATERAL. INVALIDADE. SÚMULA 83/STJ. DANO MORAL. QUANTUM INDENIZATÓRIO. REVISÃO DO CONJUNTO FÁTICO-PROBATÓRIO. IMPOSSIBILIDADE. SÚMULA 7/STJ. AGRAVO NÃO PROVIDO. 2. É ilegítima a suspensão do fornecimento de energia elétrica quando o débito decorrer de suposta fraude no medidor de energia, apurada unilateralmente pela concessionária. [...] 4. Agravo regimental 
não provido. (AgRg no AREsp 368.993/PE, Rel. Ministro ARNALDO ESTEVES LIMA, PRIMEIRA TURMA, julgado em 22/10/2013, DJe 08/11/2013) ${ }^{7}$ (Grifo nosso)

Por consequente, em havendo prejuízo ao consumidor pela atitude desidiosa e sem provas, o $\mathrm{CDC}$, no art. 22, § único leciona sobre a responsabilização dos danos pelo desrespeito das obrigações por parte das Pessoas Jurídicas.

Nesse contexto, o Judiciário dia a dia recebe inúmeras demandas individuais pleiteando reparação de consumidores, e estes casos quando analisados causuísticamente, em grande parte, demonstram as fragilidades de provas, sejam estas a falta de entrega do TOI ao consumidor, a perícia realizada unilateralmente por laboratório não respaldados pelo INMETRO, a não comunicação ao consumidor sobre a avaliação técnica, ausência de demonstração da variação de consumo ou proveito após troca de medidor, dentre muitos outros.

\section{O PANORAMA JUDICIAL DAS AÇÕES INDIVIDUAIS PERTINENTES À RESPONSABILIZAÇÃO CIVIL CONSUMERISTA}

Não de hoje as relações entre consumidores e fornecedores têm sido alteradas pela massificação do consumo e a notável ocorrência de reiteradas práticas abusivas e desleais dos detentores de maior poder na relação, os empresários. Nesse contexto, a proteção eficiente e o equilíbrio consumerista acabam conduzindo-se à uma redução significativa, dando margem ao panorama do abarrotamento das vias judiciárias através da pulverização massiva de demandas individuais similares. Por sua vez, o setor elétrico não foge à alçada, figurando-se como um dos maiores demandados em ações judiciais no Poder Judiciário.

Tal judicialização expressivamente quantitativa cinge principalmente a questões como a deficiência na regulação setorial mais incisiva, a ausência de qualidade do serviço prestado e as cobranças irregulares que recaem na suspensão do fornecimento de energia elétrica e inscrição do nome do consumidor nos órgãos de proteção (SAMPAIO; AFONSO; MEDEIROS, 2015, p. 17). Dados extraídos do relatório “Ouvidoria Setorial em Números

\footnotetext{
${ }^{7}$ BRASIL. Superior Tribunal de Justiça - STJ. AgRg no AREsp 368.993/PE. Disponível em: <https://stj.jusbrasil.com.br/jurisprudencia/24658884/agravo-regimental-no-agravo-em-recurso-especial-agrgno-aresp-368993-pe-2013-0227836-0-stj/inteiro-teor-24658885>.
} 
2018" $"$ emitido pela ANEEL demonstram a quantidade de reclamações advindas das 58 unidades distribuidoras de energia elétrica pelo Brasil, totalizando um montante de 27.346.497, somente nas esferas pré-judiciais.

Entre os Estados com maior incidência de reclamações apuradas pelo relatório ANEEL estão Rio de Janeiro, São Paulo, Porto Alegre, Belém do Pará e Belo Horizonte, sendo que entre os assuntos mais recorrentes encontram-se a falta de energia, com o equivalente a 24.531 .729 reclamações; a variação de consumo, correspondendo a 426.894 reclamações, e dentre outros a cobrança por irregularidade, compreendida em 150.301 reclamações. Ademais, quanto à resolução dessas reclamações é possível extrair os dados de que apenas 19.579 atinentes à falta de energia foram respondidas; 5.785 sobre variação de consumo e 3.134 referentes as cobranças por irregularidades.

$\mathrm{Na}$ esfera judicial o panorama das ações que englobam a temática pode ser verificado através dos dados emitidos pelo Conselho Nacional de Justiça - CNJ, por meio do relatório "Justiça em números do ano de 2018: ano-base 2017"9 , em que demonstra-se nas estatísticas que em matéria consumerista, entre os assuntos mais demandados, especificamente em segundo lugar da Justiça Estadual $-1^{\circ}$ grau de jurisdição, encontram-se cerca de 1.760 .905 processos referentes a responsabilidade do fornecedor/indenização por dano moral, sendo equivalente a $3,46 \%$ de todas as ações do Poder Judiciário.

Esse mesmo relatório demonstra ainda outros dados importantes, quais sejam: a nível de $2^{\circ}$ grau de jurisdição, os contratos de consumo correspondem a $43.037(3,55 \%$ de processos), ocupando o terceiro lugar das demandas da Justiça Estadual; nos Juizados Especiais, as demandas sobre responsabilidade do fornecedor, atingem o patamar de primeiro lugar, correspondendo a cerca de 1.234 .983 processos $(15,15 \%)$; nas turmas recursais, a mesma temática corresponde a cerca de 268.834 processos $(3,30 \%)$; e em se tratando de ações indenizatórias por danos materiais causados pelos fornecedores, nos Juizados especiais encontram-se 40.159 de processos $(3,32 \%)$.

Sampaio, Afonso e Medeiros (2015) apontam pontualmente que acerca da regulação setorial e judicialização uma das primeiras constatações extraídas de pesquisas judiciais é o fato de que na resolução judicial de tais conflitos consumidores e concessionárias de

\footnotetext{
8 Disponível em: <http://www.aneel.gov.br/documents/655804/16610727/Revista+OSN+2018_WEB.pdf/ 86e0982a-6fbf-eaae-be91-9e69d0f07a1c>. Acesso em 25 jul. 2019.

9 Para maiores informações consultar o arquivo formulado no endereço eletrônico, disponível em: http://www.cnj.jus.br/files/conteudo/arquivo/2018/08/44b7368ec6f888b383f6c3de40c32167.pdf. Acesso em: 12 mai. 2019.
} 
distribuição de energia elétrica, principalmente atinentes à variação de consumo e irregularidades na cobrança de consumo não registrado - CNR, a referência à normatização setorial da agência reguladora não constitui elemento crucial para embasar a decisão dos magistrados na maioria dos casos, menosprezando-se por consequente os regramentos emitidos pela autarquia federal responsável por fiscalizar e ditar normas reguladoras dos serviços de fornecimento de energia elétrica.

Outro fator elencado pelos autores diz respeito a concessão da indenização em face do dano moral pleiteado. Constatou-se que a maioria dos pedidos não era acolhidos, assim, das 68 decisões levantadas e analisadas no contexto da pesquisa realizada, apenas 66 pleiteavam valores indenizatórios por danos morais, contudo, o deferimento da responsabilização dos fornecedores de serviço elétrico por tal dano imaterial só obtive êxito em relação a 27 demandas.

Vislumbrando o regramento disposto no art. $6^{\circ}$, VI do CDC, não se pode esquecer da tutela à ampla e efetiva reparação de danos ao consumidor, qualquer seja sua natureza, contudo, o cenário de amparo judicial se mostra distante desse ideal, por vezes, incorrendo na banalização das pretensões por mero aborrecimento e na alegação fictícia de uma indústria do dano moral, nesse sentido, Verbicaro, Silva e Leal (2017, p. 85) explanam:

\footnotetext{
Vivemos um momento tenebroso no âmbito da tutela do consumidor, marcado pela involução legislativa, abstencionismo estatal como mediador responsável, sobretudo no âmbito de sua atividade regulatória do serviço público e na execução do poder de polícia fiscalizatório para combater as práticas abusivas do mercado, sendo muitas vezes complacente com o ilícito [...] A partir de muitas decisões desconcertantes do Judiciário brasileiro, que colocaram bens jurídicos relevantes do consumidor como a preservação de sua incolumidade, ou mesmo o direito à própria administração do seu tempo (considerado hoje o bem mais precioso numa sociedade excessivamente dinamizada e voltada para a produção econômica) num arriscado patamar de depreciação valorativa e que sugere aos agentes econômicos de consumo que atuar na infralegalidade compensa, ou seja, o custo da oportunidade de lesar o consumidor no atacado e ser condenado no varejo justifica a economia no processo produtivo e, consequentemente, no aprimoramento da qualidade e segurança dos produtos e serviços colocados no mercado de consumo. A banalização das pretensões consumeristas já revela que o Judiciário, há muito, foi destituído do então honroso posto de "bastião" da segurança jurídica no enfretamento dos problemas sociais, que agora vê o consumidor como mera estatística de produtividade e o seu respectivo advogado como terceiro interessado em dividir com os autores das múltiplas demandas pulverizadas de consumo os benefícios econômicos daquela que se tornou uma "aventura" judicial.
}

No geral, é justamente essa sobrecarga processual, os fatores apontados e outros entraves jurídicos como a duração excessiva do processo; o alto custo processual de uma ação 
individual; a ausência de órgão assistenciais gratuitos que sejam suficientes para atender as demandas consumeristas; a falta de efetividade protetiva em sede de $1^{\text {a }}$ instância; o formalismo jurídico exacerbado tendencioso aos interesses dos réus, dentre outros que acabam por não acobertar e acolher a defesa dos direitos consumeristas em sua devida extensão, incorrendo na descrença judiciária e crise de confiança por parte do mais vulnerável da relação, o consumidor, e por consequente, comprometendo a segurança e estabilidade jurídica, fazendo com que a parte lesada passe a adotar um comportamento mais comodista diante da ofensa sofrida, concorrendo para um estado de indolência social (VERBICARO, 2018, p. 84).

\section{A (IN)EFICIÊNCIA DA ANEEL E A INVOLUÇÃO DA PROTEÇÃO ADMINISTR ATIVA NAS RELAÇÕES DE CONSUMO}

Criada para fiscalizar as atividades de fomento em matéria de recursos energéticos, a Agência Nacional de Energia Elétrica - ANEEL insurge em um contexto que o Estado, ante aos crescentes atos de privatização dos serviços públicos, necessitava ultrapassar a mera função em prol do mercado e pôr em prática uma tutela mais ativista no que tangia a intervenção indireta, seja a limitação do poder de polícia sobre a atividade econômica desempenhada pelo particular, almejando assim a fiscalização, regulação e normatização dessa prestação de serviços públicos visando principalmente adequação, qualidade e segurança.

Nesse contexto, nos moldes constitucionais brasileiro do artigo 174 da CF/88 e do relevante princípio da eficiência, introduzido através da Emenda Constitucional 19/98 ${ }^{10}$, disposto no artigo 37 da mesma Carta, a imagem do Estado regulador torna-se então determinante para o setor público e indicativa no setor privado, atuando em estabelecer regras e modos fiscalizatórios ao seu cumprimento, pelo exercício de todas as atividades inerentes ao poder de polícia (DI PIETRO, 2009, p. 24).

Destarte que a criação da ANEEL se deu por meio de lei específica, quer seja a Lei ${ }^{\circ}$ 9.427/96 (BRASIL. 1996), tendo vinculação direta ao Ministério de Minas e Energias. Tal legislação, conforme disposto no artigo $2^{\circ}$, estipula como atribuições da presente agência

\footnotetext{
${ }^{10}$ A Emenda Constitucional no $19 / 98$ trouxe um novo espirito de reforma na Administração Pública, com fito de torná-la eficiente, agregando possibilidades de competições socioeconômicas pelo viés da tríplice relação entre a economia globalizada, a Administração Pública e a reforma do Estado (CAL, 2004, p.32).
} 
regulatória a ato de regular e fiscalizar geração, transmissão, distribuição e comercialização de energia elétrica, dando atenção especial ao interesse do consumidor; mediar os conflitos de interesses entre os agentes do setor elétrico e entre estes e os consumidores; conceder, permitir e autorizar instalações e serviços de energia; garantir tarifas adequadas e justas; zelar pela qualidade dos serviços; adequar os investimentos necessários ao setor e assegurar a universalização dos serviços.

Proporcionalmente à interligação entre a matéria administrativa dos serviços públicos com relação à energia elétrica e os parâmetros estabelecidos pelo CDC, salienta-se que, muito embora o Estado tenha propulsionado e evoluído o fenômeno das privatizações, a capacidade deste em termos de adaptações, normatizações e fiscalizações as necessidades coletivas não evoluiu no mesmo compasso, restando a eficiência, qualidade, segurança e continuidade completamente ignoradas pelas concessionárias face a inércia da chancela pública (VERBICARO; FREIRE, 2019, p. 130).

Logo, em outras palavras, o que torna-se possível constatar pelo transcorrer textual deste artigo, dentre outros motivos, é justamente que a existência de normatizações da ANEEL, sem a efetiva fiscalização de cumprimento destas por parte da agência reguladora perante os fornecedores de energia elétrica, ocasiona a acentuação da vulnerabilidade do consumidor na relação de consumo e a involução da proteção estatal caracterizada pela ineficiência da atuação administrativa.

Não raros os problemas consumeristas relatados atinentes à prática abusiva da cobrança de recuperação de consumo não registrado, advindos do reticente descumprimento dos termos normativos da ANEEL elenca-se como possíveis entraves colaboradores para a ineficiência da atividade regulatória o esquecimento do papel das Agências Reguladoras no direito brasileiro, verificado no desempenho complexo e burocrático dos atos compostos emitidos por esta; a nomeação por indicação sem o devido concurso público ${ }^{11}$, a ausência de um órgão que realize o controle geral acerca das agências reguladoras existentes ${ }^{12}$, dentre outros.

\footnotetext{
${ }^{11}$ Compreendemos que a burocracia gerencial configura uma das dificuldades ao controle e funcionalidade das regulatórias, deste modo, o ato de nomeação dos dirigentes das agências reguladoras por meio de indicação e não por ingresso por meio de concurso público, inviabiliza uma escolha racionalizada, calcada na priorização da igualdade de condições dos concorrentes para o exercício do cargo público.

12 No ordenamento administrativo atual inexiste ente ou órgão capacitado ao exercício do controle, regulamentação e fiscalização geral dos atos praticados pelas autarquias federais em regime especial, tornando não efetiva a manutenção do ideal em que se constituíram as reguladoras para que atuem com isenção,
} 
São os atores políticos, sociais e econômicos de cada setor que trazem à tona a diferenciação de tratamento estatal para com as demandas e os indivíduos atingidos. De pronto, são os desejos do livre mercado fomentados pelas veias capitalistas do lucro, das negociações com os representantes políticos, dos interesses de categorias e grupos que afetam a configuração institucional e as regras pelas quais e como cada agência reguladora estará submetida (PÓ; ABRUCIO, 2006, p. 688).

Nesse sentido, pode-se elucidar as palavras de Verbicaro e Freire (2019, p. 134):

\begin{abstract}
Constata-se uma total inoperância e conivência com as práticas irregulares dos fornecedores, pois basta citar o problema crônico da telefonia fixa e energia elétrica que na maioria dos Estados são disponibilizados em regime de monopólio, limitando por completo o poder de escolha e as alternativas do consumidor. A supervalorização das tarifas, por sua vez, inviabiliza o próprio acesso ao serviço, que, na maioria das vezes, não é disponibilizado de maneira adequada, segura e nem tampouco contínua, como estabelece o próprio art. 22 do CDC.
\end{abstract}

Ademais, a evidente ausência de fiscalização para com o serviço prestado pelos particulares fornecedores de serviços públicos, devida a ausência estrutural estatal e/ou má organização administrativa, é um dos maiores problemas atuais, possibilitando a permanência de concessões com fornecedores que não se põem em pé de igualdade mercadológica a oferecer que os consumidores usufruam a qualidade de seus serviços, pelos quais há efetiva contraprestação; transferindo o ônus das perdas energéticas e má gerenciamento na prestação de seus serviços, perceptíveis nos casos de ausência de vistorias e inspeções capazes de identificar as boas condições de continuidade e conformidade aos padrões de medição, ultrapassagem do limite de prazo para troca de medidores, variações de consumo por interrupções frequentes por causas não atribuíveis ao consumidor, dentre outros.

Além disso, muito embora a ANEEL tenha efetuado maiores planejamentos quanto a organização e disposição ao consumidor de meios eficientes e gratuitos de atendimento às reclamações em seu sítio eletrônico, como um instrumento prévio para a solução do conflito, evitando a formação de uma demanda judicial e de fomento à participação da sociedade civil quanto ao feedback dos serviços, o acesso à tal informação alternativa ainda se propaga a passos curtos entre os sujeitos, e por vezes, há uma demora considerável na resposta da

imparcialidade e comprometimento. Ademais, tal reticência da máquina gerenciadora provoca a discussão sobre a atividade regulatória se calcar pró-mercado, transparecendo uma figura inerte face à efetividade e eficiência das fiscalizações, bem como do dinamismo do controle por meio de sanções aos descumprimentos. 
solicitação, conduzindo o consumidor a buscar outras vias que possam solucionar os problemas com as concessionárias de energia elétrica.

Trazer à exposição a nítida decadência estatal e a imediata necessidade de maior fiscalização por parte das agências reguladoras é fomentar a discussão sobre a responsabilidade civil conjunta do Estado e das fornecedoras para com as inúmeras cobranças abusivas que assolam o Judiciário em demandas individualizadas e envolvem a proteção administrativa do consumidor na relação de consumo, ao passo que desrespeitam o ônus da prova, e dentre outros, os moldes do art. 22 e 39 do CDC. É, ainda, ressaltar problemáticas sobre os reais compromissos do Estado em aferir se realmente aquele parâmetro de indexação e imposição de cobranças é o mais coerente com a realidade econômica dos consumidores e com a qualidade da prestação do fornecimento de energia oferecido.

\section{A NECESSIDADE DE FORTALECIMENTO DA TUTELA COLETIVA EM PROL DA DEFESA DOS DIREITOS METAINDIVIDUAIS CONSUMERISTAS}

Em um cenário de reticentes problemáticas de usuários com relação as prestações de serviços pelas concessionárias de energia elétrica, abarrotamento de demandas individuais similares no Judiciário pleiteando pela responsabilização e indenização e ausência de uma atuação eficiente da ANEEL, a defesa dos direitos metaindividuais fundamentais dos consumidores acaba se tornando algo em segundo plano. Nessa esteira, elenca-se o fortalecimento da tutela coletiva, por meio dos legitimados extraordinários, como um mecanismo de melhor acesso ao judiciário e resolução de lides consumeristas.

De pronto, não significa dizer que com a adoção da tutela coletiva haverá o esquecimento e o ato de ignorar os pleitos individuais em juízo, de modo a somente ser possível o acesso judicial pelas vias coletivas, mas sim, pautar a defesa dos direitos transindividuais consumeristas na sua concreta amplitude, possibilitando salvaguardar o ideal de solidariedade, a rapidez da entrega da prestação jurídica, o acesso à justiça e a fuga da pulverização de demandas em que há a banalização e aviltamento das pretensões.

Verbicaro (2017, p. 743) elucida que:

Com o surgimento da lei 8.078/90 (Código de Defesa do Consumidor - CDC), houve uma opção muita clara do legislador pelo reconhecimento e instrumentalização dos interesses transindividuais, não apenas como nova expressão plural de um direito solidário, mas também porque se previa a impossibilidade gerencial do Judiciário lidar com o crescimento exponencial dos conflitos de 
consumo, cuja pulverização individual inviabilizaria o próprio reconhecimento jurisdicional satisfatório, levando à banalização da proteção normativa do consumidor. Isso, também, macularia a imagem do Judiciário como última fronteira na proteção do consumidor, enquanto parte economicamente vulnerável na relação de consumo, pois não teria condições operacionais de processar e responder em tempo razoável tantas provocações individuais e crescentes.

Conquanto à tutela coletiva, o legislador brasileiro se inspirou nos moldes das class actions for damages norte-americanas, destinando a utilização desta para a proteção de interesses metaindividuais que são compartilhados por titularidades determináveis ou indetermináveis, reunidos pela mesma relação de fato e/ou de direito, classificados entre difusos $^{13}$, coletivos em sentido estrito ${ }^{14}$ e individuais homogêneos ${ }^{15}$, em conformidade com a redação do texto constitucional do art. 129, III e do art. 81 e incisos I, II e III do CDC.

Por consequente, a nova racionalidade coletiva para a adequada solução dos conflitos consumeristas em massa trouxe consigo, no contexto legislativo do CDC no artigo 82, a possibilidade da legitimação extraordinária, pleiteando-se por meio de substitutos processuais a defesa de interesse alheio em nome próprio, quebrando o paradigma do modelo clássico processual individualista imposto pelo Código de Processo Civil, até então de 1973, e o Código Civil de 2002.

Desta forma, consideram-se legitimados extraordinários concorrentes à causa os Ministérios Públicos; a União, os Estados, os Municípios e o Distrito Federal; as entidades e órgãos da Administração Pública direita ou indireta, ainda que sem personalidade jurídica, mas desde que sejam especificamente destinadas à defesa dos consumidores e as associações legalmente constituídas há pelo menos um ano e que incluam entre seus fins institucionais a defesa dos interesses e direitos protegidos pelo CDC.

\footnotetext{
${ }^{13}$ Os direitos difusos foram a primeira categoria de interesses metaindividuais reconhecida pelo ordenamento jurídico brasileiro. Caracterizados por serem abstratos, com sujeitos indeterminados, quer seja que atingem à coletividade de consumidores em geral, indivisíveis em termos de fracionamento do objeto e internamente litigiosos entre todos os sujeitos direta ou indiretamente atingidos pelo reconhecimento desse interesse (VERBICARO, 2019, P. 335-336).

${ }^{14}$ Por sua vez, os direitos coletivos em sentido estrito serão havidos quando reconhecida uma relação jurídica concreta preexistente à lesão ou à ameaça de lesão, a qual permita situar uma limitação natural ao alcance da tutela. Desta forma, torna-se possível constar como característica a determinabilidade de sujeitos atingidos, podendo ser grupos, categorias ou classes de pessoas, quando da apuração do dano e da responsabilidade (VERBICARO, 2019, p. 338-340).

${ }^{15}$ Em se tratando de direitos individuais homogêneos, também conhecidos como direitos acidentalmente coletivos, estes decorrem de um interesse individual subjetivo, atinente à apenas um sujeito ou a um conjunto de particulares através do litisconsórcio ativo. Em outros termos, caracteriza-se pela origem comum, em que os sujeitos são pessoas determinadas, por consequente sendo o objeto da demanda divisível entre si, admitindo apenas a possibilidade de reparabilidade direta, estimulada pela coletivização de interesses através da instrumentalização de uma única ação coletiva, fundada na origem comum do dano e na identidade concreta da quantidade de consumidores que se encontram na mesma situação de fato (VERBICARO, 2019, p. 340-343).
} 
Por sua vez, a positivação pelo Código de Defesa do Consumidor - CDC e o compromisso do legislador para com as tutelas coletivas foi de resgatar e garantir a efetividade de proteção material dos consumidores, possibilitando através de inovações processuais, tais como, isenção de custas; inexistência sucumbencial; vedação à denunciação à lide, claramente quando for prejudicial aos interesses; inversão do ônus da prova, conforme art. $6^{\circ}$, inciso VIII do CDC; dentre outras, mudar o contexto moroso, de alto custo para demandas individuais, de formalismo processual e desamparo das pretensões legítimas pelo Judiciário ante a demandas consecutivas consumeristas.

A atuação das entidades de defesa coletivas, independente da classificação dos direitos coletivos envolvidos, ocorre assaz vezes pelo meio judicial, por meio das Ações Civis Públicas - ACP's, desenvolvidas a partir dos regramentos dispostos na Lei 7.347/85 - Lei de Ação Civil Pública, contudo, tendo em vista o panorama judicial em que se apresentam as demandas no Poder Judiciário, conforme já exposto, e a primazia por resoluções mais céleres, tais entidades têm reforçados esforços e empenhos nas resoluções extrajudiciais.

Transigir, quer seja adotar uma postura mais consensual, pode ser mais eficiente e mais favorável que o imperativo pelo litígio, tanto em termos de interesses/direitos públicos e/ou privados. Remonta-se que, muito embora a visão clássica da doutrina administrativa prepondere o zelo pelo interesse público sob o privado, implicando no cumprimento fiel ao princípio da estrita legalidade, no cenário de responsabilidade das concessionárias de energia elétrica e amparo às pretensões dos usuários é possível constatar que a conduta em sentido mais restrito e original previsto em lei, por vezes, não é capaz de solucionar da melhor forma e em menor tempo as demandas.

Diante disso, quer se dizer que, para além das atividades judiciais dos legitimados extraordinariamente para exercer a tutela coletiva, os mecanismos extrajudiciais, como os Termos de Ajustamento de Condutas - TAC's, têm ganhado cada vez mais força, de modo a intensificar a efetiva proteção dos mais vulneráveis na relação de consumo. Ademais, nestes termos, a união destes, seja a atuação conjunta dos órgãos legitimados tem sido outra alternativa qualificada para ampliar o ideal de solidariedade em prol das ações sobre relação de consumo.

Nesse sentido de uma atuação mais qualificada, pode-se perfeitamente destacar as palavras de Verbicaro (2017, p. 746): 
Quanto mais qualificada e concertada a atuação dos legitimados ativos, maiores serão as chances de decisões vantajosas para o consumidor, seja cominando o cumprimento forçado de obrigações legais e contratuais, seja revendo práticas abusivas, seja impingindo ao segmento empresarial condenações pecuniárias com forte apelo pedagógico, resultados esses mais tangíveis em demandas coletivas, que nas individuais.

O Termo de Ajustamento de Conduta - TAC trata-se justamente, nos moldes do objeto desta pesquisa e do art. $113, \S 6^{\circ}$ do $\mathrm{CDC}$, do instrumento firmado através da transação realizada entre as entidades legitimadas extraordinariamente em prol da defesa do consumidor e as concessionárias de energia elétrica, em busca da efetividade da regulação dos serviços, fiscalização pela qualidade na prestação do serviço e na cessação das práticas abusivas e cobranças irregulares, mostrando-se um mecanismo dissuasivo, com função educativa para desmotivar condutas danosas e adequado à alternatividade das vias judiciais.

Como termos exemplificativos podemos citar pontualmente o caso do TAC firmado entre o Estado do Pará e a concessionária fornecedora de energia elétrica no Estado - CELPA, celebrado através união e empenho da atuação da Procuradoria do Estado - PGE/PA, da Defensoria Pública - DPE/PA e do Ministério Público - MP/PA, na qual acerca da defesa dos consumidores firmaram-se as seguintes obrigações da concessionária: cumprimento do regramento do art. 115 ou 130 da Resolução 414/2010 da ANEEL para o cálculo devido do valor de consumo não registrado - CNR ; não efetivação de suspensão do fornecimento de energia elétrica por inadimplemento de CNR; não condicionar o religamento do serviço elétrico aos débitos de CNR que superem 3 ciclos; negociação de débitos de qualquer natureza; não efetuar lançamento, a título de acúmulo de consumo, sem antes informar aos consumidores o valor a ser cobrado e oferecer-lhes a possibilidade de quitação; fornecimento de canais de atendimento ao consumidor virtuais e aplicativo que proponham resoluções extrajudiciais através de mediação e conciliação; nos processos relativos a casos que foram constatadas irregularidades nos medidores, mas inexista laudo pericial emitido por laboratório credenciado ao INMETRO ${ }^{16}$, o cancelamento das faturas reclamadas, dentre outras medidas.

Firmou-se ainda, a termo de penalidade pelo descumprimento das obrigações assumidas, a aplicação de multa correspondente ao valor de $\mathrm{R} \$ 5.000$ (Cinco mil reais) pelas infrações ocorridas. Ademais, outro ponto extremamente relevante decorrente do TAC supramencionado tange exatamente no compromisso da CELPA em efetuar o pagamento do

\footnotetext{
${ }^{16}$ O Instituto Nacional de Metrologia, Qualidade e Tecnologia - INMETRO é uma autarquia federal, vinculada ao Ministério da Economia, tendo função fiscalizatória e normativa acerca da melhoria e controle de qualidade de produtos e/ou serviços.
} 
valor de $\mathrm{R} \$ 1.000 .000,00$ (Um milhão de reais) à título de compensação social pelos danos já ocasionados aos consumidores, destinando-se em iguais frações às entidades de apoio e orientação dos consumidores, tais como no caso paraense à Procuradoria Geral do Estado PGE/PA, Defensoria Pública do Estado - DPE/PA, PROCON/Secretaria de Justiça e Direitos Humanos - SEJUDH, ao Ministério Público do Estado - MPE/PA; e à entidades educativas das relações consumeristas responsáveis por projetos de pesquisas e extensão relacionados à proteção dos vulneráveis e difusoras de informações qualificadas acerca dos direitos básicos positivados no CDC, como no caso, a Universidade Federal do Pará - UFPA, especificamente ao Instituto de Ciências Jurídicas - ICJ.

Em síntese, enfatiza-se que o reconhecimento e necessidade de fortalecimento da tutela coletiva traz consigo a possibilidade de proporcionar uma proteção mais incisiva quanto aos direitos da coletividade, a qual individualmente na esfera judicial não consegue instrumentalizar mudanças perceptíveis, com relação a mudança de comportamento danoso das concessionárias de energia elétrica. Deste modo, pleitear coletivamente, quer seja pelos meios judiciais ou extrajudiciais, impacta diretamente na defesa da parte vulnerável da relação de consumo e em punir o fornecedor que pratica e/ou praticou a conduta ilícita sem dimensão de quem virá atingir, impossibilitando este de locupletar-se dos lucros obtidos com a conduta danosa, fazendo-o responder em juízo ou extrajudicialmente pelo prejuízo coletivo que causou, por consequente, desmotivando prática ilícita similares no futuro.

\section{CONCLUSÃO}

As relações de consumo decorrentes do fornecimento de energia elétrica pelas concessionárias são cada vez mais frequentes na sociedade, bem como as cobranças por supostas fraudes aos medidores das unidades consumidoras imputados, na grande maioria das vezes, de maneira unilateral ao consumidor. Frente ao fundamento dos ensinamentos jurídicos acerca de que o ônus da prova e das regulamentações emitidas pela Agência Nacional de Energia Elétrica - ANEEL, o mínimo a ser realizado pelas concessionárias de energia seria a prudência quanto ao procedimento apurativo de adulteração de medidores, não competindo a estas a mera alegação de débito por recuperação de consumo ao usuário do serviço, uma vez que conforme os fundamentos do CDC o consumidor é parte vulnerável e hipossuficiente na relação. 
Considerando que a recuperação de consumo "forçada" pode ocasionar graves danos ao consumidor, à guisa a suspensão no fornecimento de energia e a inscrição do nome do usuário nos cadastros de proteção de crédito, torna-se possivelmente admissível as demandas no Judiciário pleiteando indenizações contra as concessionárias. Contudo, o contexto judicial e a fixação processual na pulverização de demandas individuais colaboram para um cenário de maior morosidade e menor eficácia na resolução dos verdadeiros problemas consumeristas, não inibindo a continuação das reiteradas condutas danosas por parte dos fornecedores para com os inúmeros consumidores expostos aquela prática, assim então, constando-se decisões massivas que refletem unicamente uma visão distorcida acerca dos pleitos judiciais e o amparo às lesões no atacado e as condenações no varejo, principalmente no que atine aos danos morais.

Por consequente, pode-se entender por todo o exposto que a atuação da ANEEL em termos fiscalizatórios dos serviços prestados pelas concessionárias de serviços públicos tem sido ineficiente, demonstrando-se o esquecimento do papel para qual fora criada por meio do desempenho complexo e burocrático dos atos compostos emitidos por esta; da nomeação por indicação sem o devido concurso público , a ausência de um órgão que realize o controle geral acerca das agências reguladoras existentes, dentre outros.

Desta forma, ainda que a nítida decadência estatal esteja configurada por meio da falha na atividade regulatória, não se pode permitir a ocorrência de danos em massa e a permeabilidade econômica meramente com interesses capitalistas de lucro se sobrepondo aos interesses dos vulneráveis, logo, nessa toada, o fortalecimento da tutela coletiva e das entidades legitimadas extraordinariamente insurge como uma forte alternativa ao tratamento das demandas e soluções eficazes aos problemas do setor elétrico.

Portanto, são as atuações qualificadas da tutela que foge à esfera meramente individual em prol da coletividade que proporcionam na atualidade uma proteção mais efetiva ao consumidor, reforçando a instrumentalidade da punição pelos danos e necessidade de mudança no comportamento do ofensor, dimensionando e guiando o consumidor a resgatar o espírito solidário através do consumo e a quebra do comodismo face a cobrança por irregularidades não devidas.

\section{REFERÊNCIAS}


ALVES, Danielle Oliveira. TORQUATTO, Carla Cristina Alves. Energia Elétrica: Irregularidades no consumo e seus impactos na sociedade. Disponível em: < http://www.publicadireito.com.br/artigos/?cod=c9c10e15bf0575c5>. Acesso em 25 de Abril de 2017.

ANEEL - Agência Nacional de Energia Elétrica. Resolução 456. Condições Gerais de Fornecimento de Energia Elétrica, 2000.

ANEEL - Agência Nacional de Energia Elétrica. Resolução 414. Novas Diretrizes e Condições de Fornecimento de Energia Elétrica, 2010.

BANDEIRA DE MELO, Celso Antônio. Curso de Direito Administrativo. Editora Malheiros: $32^{\mathrm{a}}$ edição, 2015.

BRASIL. Agência Nacional de Energia Elétrica - ANEEL. Ouvidoria setorial em números 2018: aspectos técnicos e comerciais. Brasília: ANEEL, 2018. Disponível em: <http://www.aneel.gov.br/documents/655804/16610727/Revista+OSN+2018_WEB.pdf/86e0 982a-6fbf-eaae-be91-9e69d0f07a1c>. Acesso em: 30 jul. 2019.

BRASIL. Constituição da República Federativa do Brasil. $16^{\circ}$. ed. atual e ampl. São Paulo: Saraiva, 2016.

BRASIL. Lei 5.172 de 25 de outubro de 1966. Código Tributário Nacional - CTN.

Disponível em: < http://www.planalto.gov.br/ccivil_03/leis/15172.htm>. Acesso em: 20 jun. 2019.

BRASIL. Lei 8.078 de 11 de setembro de 1990. Código de Defesa do Consumidor - CDC. Disponível em: < http://www.planalto.gov.br/ccivil_03/leis/L8078.htm>. Acesso em: 20 jun. 2019.

BRASIL. Lei 8.987 de 13 de fevereiro de 1995. Regime de concessão e permissão da prestação de serviços públicos. Disponível em: < http://www.planalto.gov.br/ccivil_03 /LEIS/L8987cons.htm>. Acesso em: 20 jun. 2019.

CAL, Arianne Brito Rodrigues. As Agências Reguladoras no Direito Brasileiro. Rio de Janeiro: Renovar, 2003.

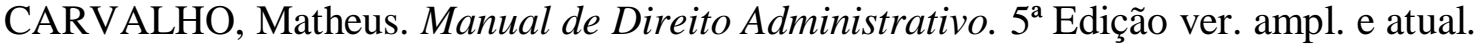
Salvador: JusPODIVM, 2018.

DI PIETRO, Maria Zanella. Direito Regulatório: Temas Polêmicos. $2^{\mathrm{a}}$ Ed. rev. e ampl. $1^{\mathrm{a}}$ reimpressão. Belo Horizonte: Fórum, 2009.

DE MATOS, Patrick Lima. A recuperação de energia e a irregularidade do medidor. Disponível em: < https://correamattos.jusbrasil.com.br/artigos/166442728/a-recuperacao-deenergia-e-a-irregularidade-do-medidor>. Acesso em: 23 de Abril de 2017.

NUNES, Luis Antônio Rizzato. Curso de Direito do Consumidor. $12^{\text {a }}$ Edição rev. e atual. São Paulo: Saraiva, 2018. 
SAMPAIO, Patrícia Regina Pinheiro; AFONSO, Marjorie Gressler; MEDEIROS, Maria Eduarda. Os conflitos, a regulação e o direito do consumidor. Coordenador Ricardo Morishita Wada. Rio de Janeiro: Escola de Direito do Rio de Janeiro da Fundação Getulio Vargas, 2015, p. $14-105$.

VERBICARO, Dennis. A defesa processual coletiva do consumidor como expressão dos direitos da solidariedade. Revista Juris Poiesis, v. 21, p. 68-90, 2018.

VERBICARO, Dennis. Consumo e Cidadania: identificando espaços políticos de atuação qualificada do consumidor. $2^{\text {a }}$ edição. Rio de Janeiro: Lumen Juris, 2019.

VERBICARO, Dennis. A tutela processual coletiva do consumidor a partir da atuação concertada dos legitimados ativos. Revista Jurídica Cesumar: Mestrado (online), v. 17, p. 741-772, 2017.

VERBICARO, Dennis; FREIRE, Gabriela Ohana Rocha. A perda da influência estatal nas relações de consumo e a involução da proteção administrativa daí decorrente. In: Aires José Rover[et al.] (coords.). (Org.). Direito, governança, novas tecnologias e desenvolvimento econômico sustentável, globalização e transformações na ordem social e econômica. $1^{\text {a }}$ ed. Zaragoza: Prensas de la Universidad de Zaragoza, 2019, v. 18, p. 118-140.

VERBICARO, Dennis; PENNA E SILVA, João Vitor; LEAL, Pastora do Socorro Teixeira. O mito da indústria do dano moral e a banalização da proteção jurídica do consumidor pelo Judiciário brasileiro. Revista de Direito do Consumidor. Volume 114. Ano 26. São Paulo: Editora RT, nov. - dez. 2017, p. 75-99. 